\title{
ANALISA PENERAPAN GEDUNG BANGUNAN HIJAU PADA TAHAP PELAKSANAAN KONSTRUKSI
}

\section{Tri Rahmi Nurman}

Program Studi Teknik Sipil Universitas Pancasila Jakarta, Indonesia

Email: rahmitri38@gmail.com

\begin{abstract}
Abstrak
Dengan adanya permen PUPR No 2 tahun 205 dan SE no 86 tahun 2016 menggalakkan konsep bangunan gedung yang ramah lingkungan, yang merupakan upaya pemerintah dalam menggalakkan konsep bangunan gedung yang ramah lingkungan. Konsep gedung bangunan hijau, yaitu konsep pengelolaan lingkungan hidup diwilayah pasar dengan melibatkan semua civitas disekitarnya, merupakan salah satu bangunan yang mencakup penerapan konsep green building, yaitu konsep pengelolaan lingkungan. Penelitian ini bertujuan untuk mengevaluasi sejauhmana penerapan gedung bangunan hijau pada gedung Pasar Rakyat kota Pariaman dan mengevaluasi tingkat keberhasilan penerapan green building pada gedung Pasar Rakyat Kota Pariaman. Metode penelitian yang dilakukan dengan menggunakan metode kualitatif dengan cara melakukan wawancara dan pengisian kuesioner. Berdasarkan data dan perhitungan pada gedung Pasar Rakyat Kota Pariaman terdapat 10 kriteria Bangunan Gedung Hijau (BGH), gedung yang dimaksud memiliki total jumlah poin 64 dari maksimal 100. Akibatnya, gedung dianggap belum memenuhi kriteria sebagai gedung baru yang menerapkan konsep green building seperti SE no 86 tahun 2016 memiliki nilai standar pemenuhan rating sebesar 70-75 poin untuk peringkat Plakat Pratama.
\end{abstract}

Kata Kunci: gedung bangunan hijau; Permen PUPR no 2 tahun 2015; se no 86 tahun 2016; pasar rakyat kota pariaman

\section{Abstract}

With the pupr candy No. 2 of 205 and SE no. 86 of 2016 encourages the concept of environmentally friendly buildings, which is the government's effort in promoting the concept of environmentally friendly buildings. The concept of green building building, which is the concept of environmental management in the market region by involving all the surrounding community, is one of the buildings that includes the application of the concept of green building, namely the concept of environmental management. This research aims to evaluate the extent of the application of green buildings in the Pariaman city People's Market building and evaluate the success rate of green building implementation in the Pariaman City People's Market building. Research methods are carried out using qualitative methods by conducting interviews and filling out questionnaires. Based on data and calculations on the Pariaman City People's Market building there are 10 criteria for Green Building Building (BGH), the building in question has a total number of points of 64 out of a maximum of 100. As a result, the building is considered not to meet the criteria as a new building that applies the concept of green building such

$\begin{array}{ll}\text { How to cite: } & \text { Nurman. T. R., (2021) Analisa Penerapan Gedung Bangunan Hijau pada Tahap Pelaksanaan } \\ & \text { Konstruksi, Syntax Idea, 3(10), https://doi.org/10.36418/syntax-idea.v3i10.1388 } \\ \text { E-ISSN: } & \text { 2684-883X } \\ \text { Published by: } & \text { Ridwan Institute }\end{array}$


as SE no. 86 of 2016 has a standard rating of 70-75 points for the Pratama Plaque rating.

Keywords: green building; pupr ministerial regulation no 2 of 2015; se no 86 of 2016; pariaman city people's market

\section{Pendahuluan}

Alam dan lingkungan telah berubah dan masalah lingkungan, termasuk pemanasan global, telah menjadi fenomena. Pemanasan global adalah peningkatan suhu dan suhu rata-rata lapisan atmosfer, daratan, dan lautan di permukaan bumi. Disebabkan oleh konstruksi bangunan atau efek rumah kaca (Pratama, 2019).

Arsitektur / Bangunan hijau merupakan gerakan moral. Konsep green building yang telah dirumuskan dalam sistem rating oleh lembaga-lembaga 'hijau', telah menjadi bagian dari market/pasar dan trend bangunan yang dilatarbelakangi oleh kesadaran yang semakin tinggi dari warganya untuk mulai peduli dengan lingkungan (Nugroho, 2011).

Bangunan adalah bentuk fisik dari proyek konstruksi yang menyatu dengan tempat tinggal, sebagian atau seluruhnya berada di atas dan/atau di dalam tanah dan/atau air, yang berfungsi sebagai tempat manusia melakukan kegiatannya, baik untuk hunian atau tempat tinggal, kegiatan keagamaan, kegiatan usaha, kegiatan sosial, budaya, maupun kegiatan khusus (Beda, 2014).

Pemanasan global, perubahan iklim dan konsumsi sumber daya alam secara terus menerus menyebabkan sumber daya alam menjadi rusak dan semakin terbatas, maka konsep bangunan hijau ini dan menjadi salah satu solusi untuk mencegah kerusakan alam lebih lanjut. bangunan hijau tidak hanya dilihat sebagai sebuah produk jadi, namun keseluruhan proses untuk merencanakan dan membangun bangunan tersebut. Keberhasilan penyelenggaraan suatu proyek konstruksi akan sangat bergantung kepada kualitas mereka yang menangani proyek tersebut terutama yang memegang posisi kunci (Mulyadi, 2012).

Salah satu upaya yang dapat dilakukan adalah green building atau bangunan ramah lingkungan, khususnya pembangunan gedung-gedung di Indonesia yang berkembang pesat dan kebutuhan energi juga semakin meningkat. Bangunan hijau mengacu pada bangunan yang menerapkan prinsip bangunan hijau menurut klasifikasi, memenuhi persyaratan konstruksi, dan memiliki kinerja terukur yang signifikan dalam hal penghematan energi, penghematan air, dan sumber daya lainnya (Mahyuddin, Rilatupa, \& Marpaung, 2020).

Standar untuk menentukan layaknya bangunan tersebut disebut sebagai bagunan gedung hijau atau green building. Penulis akan berorintasi pada Permen PUPR no 2 tahun 2015 dan SE no 86 tahun 2016, karena pada proyek pasar rakyat kota Pariaman ini digunakan dua acuan tersebut untuk dilakukannya penilaian proyek sebagai bagunan gedung hijau. Dimana dua aturan tersebut menjelaskan apa saja persyaratan dan penerapan yang tepat untuk bangunan tersebut sehingga layak disebut bagunan gedung 
hijau, serta terdapat form penilaian untuk menganalisis berapa poin yang didapatkan oleh gedung tersebut untukk memenuhi nilai layak menjadi bangunan gedung hijau.

Adapun maksud dan tujuan penelitian ini adalah sebagai berikut : (1.) Menganalisis implementasi konsep green berdasarkan Permen PUPR no 2 tahun 2015 dan SE no 86 tahun 2016 Pada Gedung Pasar Rakyat Kota Pariaman. (2.) Menganalisis jumlah nilai yang didapatkan proyek pasar Rakyat kota Pariman dalam penerapan bangunan gedung hijau berdasarkan Permen PUPR no 2 tahun 2015 dan SE no 86 tahun 2016.

\section{Metode Penelitian}

Penelitian ini akan dilakukan pada gedung Pasar Rakyat Kota Pariaman yang berlokasi di jalan St. Syahrir Kelurahan Kampung Perak, Pariaman Tengah, Kota Pariaman, Sumatera Barat.

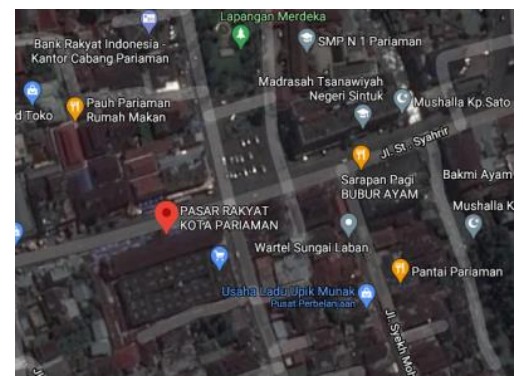

Gambar 1

\section{Lokasi Pasar Rakyat Kota Pariaman Sumatera Barat}

Sumber data harus ditentukan selama penyelidikan. Data adalah tentang informasi, fakta-fakta, atau simbol-simbol yang menjelaskan tentang objek (Duane, 2016). Data primer penelitian ini diperoleh dengan melakukan wawancara dan pengisian kuesioner untuk mengetahui konsep bangunan hijau secara umum dan untuk memastikan keberhasilan kuesioner yang telah dibuat nara sumber sebelumnya. Data primer dalam penelitian ini diperoleh dengan wawancara staff Wika Gedung yang bekerja di proyek Pasar Rakyat Kota Pariaman. Dara sekunder yaitu data yang diperoleh dalam bentuk yang sudah siap atau jadi, sudah dikumpulkan dan diolah serta sudah dipunlikasi oleh pihak yang lain (Perdana, Agustino, Hartawan, Suyoso, $\&$ Sari, 2020). Sumber data sekunder dalam penelitian ini dilihat dari dokumentasi perusahaan sebagai pendukung dari beberapa dokumen perusahaan dan literatur, serta informasi lain yang mendukung dalam penelitian ini. Informasi ini digunakan sebagai data primer. 


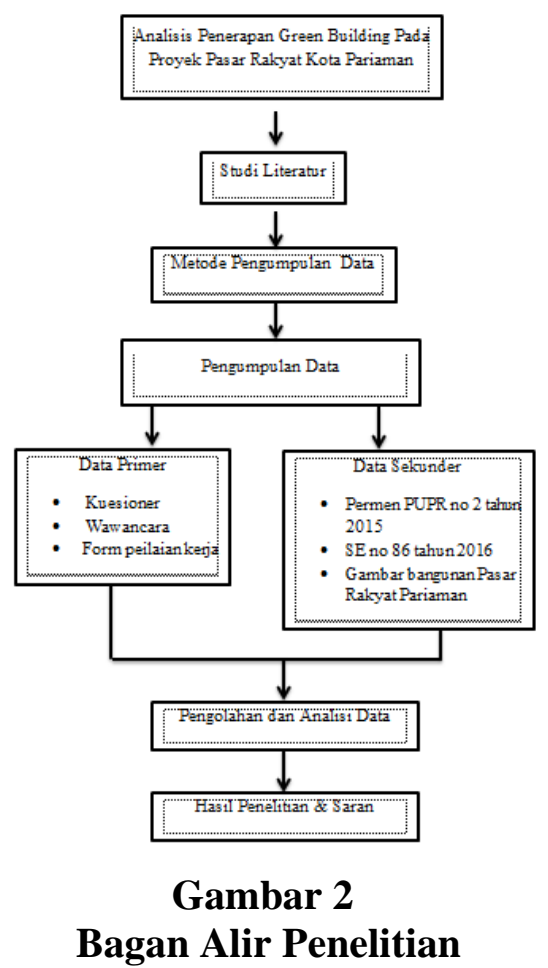

Metode Pengumpulan Data yang digunakan adalah, (1.) Wawancara Teknik wawancara terstruktur digunakan untuk teknik pengumpulan data, jika peneliti atau pengumpul data sudah mengetahui informasi pasti apa yang akan diperoleh. Oleh karena itu, dalam melakukan wawancara, pengumpul data telah menyediakan instrumen penelitian berupa pertanyaan tertulis yang alternatif jawabannya telah disediakan (Anggito \& Setiawan, 2018) (2.) Dokumentasi Metode dokumentasi digunakan untuk mengumpulkan data pelaksanaan di proyek pasar rakyat kota Pariaman. Dokumentasi digunakan untuk mempelajari berbagai jenis dokumentasi, terutama yang ditemukan dalam proyek yang sedang dikerjakan. Dokumen lama digunakan dalam penelitian sebagai sumber data karena dalam banyak dokumen sebagai sumber data yang digunakan untuk pengujian, interpretasi, dan bahkan digunakan untuk meramalkan (Zed, 2012) (3.) Metode Analisa Data, Studi ini menggunakan paradigma analisis data interaktif yang dikembangkan oleh Miles dan Huberman, dan berkembang dari pengumpulan data melalui analisis data, termasuk reduksi data, penyimpanan data, dan analisis data di bagian akhir. Selama pengumpulan data putaran pertama, peneliti berusaha untuk mendapatkan informasi yang relevan dari sumber untuk menggunakannya sebagai dasar untuk menganalisis topik yang telah diidentifikasi oleh peneliti sebelum dimulainya pengumpulan data. Reduksi data adalah pengumpulan data, yaitu peneliti berusaha mendapatkan data yang sesuai dengan informan yang dapat dijadikan acuan atau dasar penelitian terhadap suatu topik yang telah ditentukan oleh peneliti sebelum penelitian (Wijaya, 2020). Peneliti mengolah data yang masih dalam bentuk setengah jadi yang sudah sama dalam tulisan dan sudah memiliki alur untuk topik yang jelas. Matriks yang nantinya ditunjukkan untuk menarik suatu kesimpulan (Wijaya, 2020). 
Peneliti usulkan uraian jawaban-jawaban terhadap tujuan penelitian berdasarkan hasil penelitian yang telah peneliti lakukan dalam proses penelitian, and akhirnya peneliti memberikan penjelasan tentang kesimpulan dan jawaban dalam pertanyaan penelitian (Setyosari, 2016).

Tabel 1

Kuisioner form penilaian ketercapaian penerapan gedung bangunan hijau proyek pasar rakyat kota Pariaman

\begin{tabular}{llcc}
\hline No & Persyaratan & \multicolumn{2}{c}{ Point } \\
\hline 1. & Metode Pelaksanaan Kontruksi Hijau: & Rencana & Realisasi \\
\hline & a. Memiliki Jadwal pelaksanaan Kontruksi & 1 & 1 \\
\hline \multicolumn{2}{l}{ b. Melakukan evaluasi kinerja Secara berkala } & 1 & 1 \\
\hline \multicolumn{2}{l}{ c. Melakukan perbaiakn atau dasar evaluasi } & 1 & 1 \\
\hline $\begin{array}{l}\text { d. Memiliki bukti yang menunjukan inovasi-inovasi } \\
\text { dalam proses }\end{array}$ & 1 & \\
\hline & Total & 4 & 3
\end{tabular}

Dari 4 (empat) tolak ukur metode pelaksanaan konstruksi hijau, hanya 3 poin rencana yang terealisasikan. Terdapat 1 (satu) tolak ukur yang tidak memenuhi nilai rencana yaitu bukti yang menunjukkan inovasi-inovasi dalam proses konstruksi dimana proyek pasar rakyat pariaman ini tidak melakukan inovasi pada proses konstruksinya sehingga hanya mendapatkan 3 (tiga) poin yang terealisasi dari 4 (empat) poin rencana.

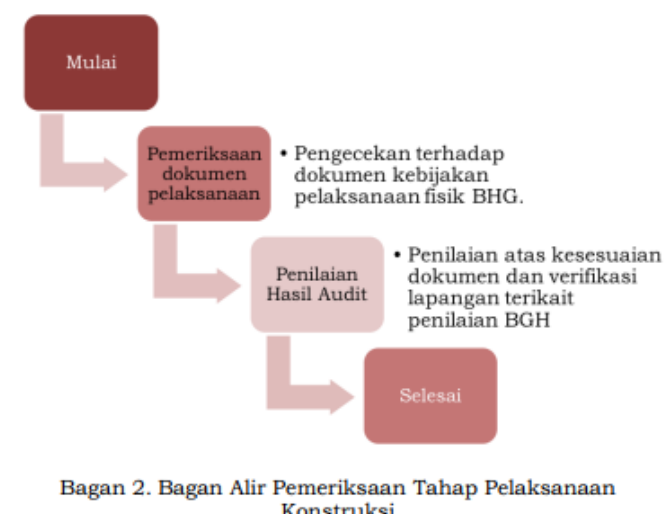

Gambar 3

Bagan alir pemeriksaan tahap pelaksanaan konstruksi

Tata cara penilaian kinerja BGH pada tahap pelaksanaan teknis meliputi 3 aspek, yaitu: Proses konstruksi hijau, praktik perilaku hijau, dan rantai pasok hijau. Pemeriksaan dilakukan terhadap dokumen teknis pelaksanaan Bangunan Gedung terhadap aspek BGH yang ada pada bangunan dan metode dalam proses konstruksinya terkait dengan lingkungan. Ketentuan lebih lanjut mengenai kondisi minimum persyaratan teknis BGH mengikuti aturan yang berlaku di daerah masing-masing (Joga, 2017). 


\section{Hasil dan Pembahasan}

\section{Proses Konstruksi Hijau}

Pada proses konstruksi ini bertujuan untuk memaksimalkan teknologi dan cara kerja agar mendapatkan nilai kerja yang ingin dicapai dengan cara mengurangi atau meminimalkan limbah yang dihasilkan saat prosses konstukri berlangsung. Pada tahap ini terdapat beberapa poin untuk memenuhinya, yaitu sebagai berikut:

a. Metode pelaksanaan konstruksi hijau

Maksud dari kategori penerapan konstruksi hijau adalah penerapan konstruksi dengan mempertimbangkan minimalisasi emisi/polutan atau dampak negatif terhadap lingkungan di sekitar lokasi konstruksi (Saidal Siburian \& Mar, 2020).

Tabel 2

Kuisioner form penilaian ketercapaian penerapan gedung bangunan hijau proyek pasar rakyat kota Pariaman

\begin{tabular}{llcc}
\hline No & \multicolumn{1}{c}{ Persyaratan } & \multicolumn{2}{c}{ Point } \\
\hline 1. & Metode Pelaksanaan Kontruksi Hijau: & Rencana & Realisasi \\
\hline \multicolumn{2}{l}{ a. Memiliki Jadwal pelaksanaan Kontruksi } & 1 & 1 \\
\hline \multicolumn{2}{l}{ b. Melakukan evaluasi kinerja Secara berkala } & 1 & 1 \\
\hline \multicolumn{2}{l}{ c. Melakukan perbaiakn atau dasar evaluasi } & 1 & 1 \\
\hline $\begin{array}{l}\text { d. Memiliki bukti yang menunjukan inovasi-inovasi } \\
\text { dalam proses }\end{array}$ & 1 & \\
\hline & Total & 4 & 3
\end{tabular}

Dari 4 (empat) tolak ukur metode pelaksanaan konstruksi hijau, hanya 3 poin rencana yang terealisasikan. Terdapat 1 (satu) tolak ukur yang tidak memenuhi nilai rencana yaitu bukti yang menunjukkan inovasi-inovasi dalam proses konstruksi dimana proyek pasar rakyat pariaman ini tidak melakukan inovasi pada proses konstruksinya sehingga hanya mendapatkan 3 (tiga) poin yang terealisasi dari 4 (empat) poin rencana.

b. Pengoptimalan penggunaan peralatan

Tujuan dari optimalisasi penggunaan peralatan yang digunakan untuk mendukung konstruksi BGH adalah untuk memberikan keselamatan dan pekerjaan yang baik. Eksposisi membangun rumah tidak terpengaruh oleh kesehatan seseorang, sebagai komponen lingkungan. Bukti berupa sertifikat dan izin sebagai jaminan keabsahan penggunaan peralatan yang aman selama $\mathrm{BGH}$. 
Tabel 3

Kuisioner form penilaian ketercapaian pengoptimalan penggunaan peralatan

\begin{tabular}{llcc}
\hline No & \multicolumn{1}{c}{ Persyaratan } & \multicolumn{2}{c}{ Point } \\
\hline 1. & Pengoptimalan Penggunaan Peralatan & Rencana & Realisasi \\
\hline \multicolumn{2}{l}{ a. Memiliki jadwal operasi alat-alat berat } & 1 & 1 \\
\hline & $\begin{array}{l}\text { b. Seluruh alat berat memiliki jadwal pemeliharaan } \\
\text { c. Seluruh alat berat memiliki izin kelayakan fungsi }\end{array}$ & 1 & 1 \\
\hline d. Seluruh operator alat berat memiliki sertifikat izin & 1 & 1 \\
\hline $\begin{array}{l}\text { e. Berhasil meminimalkan waktu jeda operasional alat } \\
\text { berat }\end{array}$ & 1 & \\
\hline & Total & 5 & 4
\end{tabular}

Dari 5 (lima) tolak ukur pengoptimalan penggunaan peralatan, hanya 4 (empat) poin rencana yang terealisasikan. Terdapat 1 (satu) tolak ukur yang tidak memenuhi nilai rencana yaitu meminimalkan waktu jeda operasional alat berat dimana proyek pasar rakyat pariaman ini tidak melakukan ini dikarenakan area sekitarnya adalah area pasar pusat belanja kebutuhan sehari-hari rakyat pariaman sehingga penggunaan alat berat hanya bisa dilakukan di malam hari karena itu jeda operasional alat berat cukup memakan waktu yang banyak. Sehingga hanya mendapatkan 4 (tempat) poin yang terealisasi dari 5 (lima) poin rencana.

\section{c. Penerapan manajemen pengelolaan limbah konstruksi}

Pengelolaan limbah konstruksi berupa limbah yang dihasilkan selama proses berlangsung, baik material maupun limbah di lingkungan proyek.

Tabel 4

Kuisioner form penilaian ketercapaian penerapan manajemen pengelolaan

\begin{tabular}{|c|c|c|c|}
\hline No & Persyaratan & & \\
\hline 1. & Penerapan Manajemen Pengelolan Limbah Kontruksi & Rencana & Realisasi \\
\hline & a. Melakukan optimasi dalam pemakaian material & 3 & \\
\hline
\end{tabular}




\begin{tabular}{llc}
\hline $\begin{array}{l}\text { sehingga menciptakan pengurangan timbunan sampah } \\
\text { kontruksi }\end{array}$ & 3 & 3 \\
\hline $\begin{array}{l}\text { b. Memiliki area pemilahan dan pengumpulan sampah } \\
\text { kontruksi }\end{array}$ & 2 & 2 \\
\hline $\begin{array}{l}\text { c. Memiliki tempat penyimpanan material yang aman } \\
\text { sehingga dapat meningkatkan usia material }\end{array}$ & 3 \\
\hline d. Terdapat laporan pendaur ulangan sampah kontruksi & 13 \\
\hline \multicolumn{2}{c}{ Total } \\
\hline
\end{tabular}

Dari 4 (empat) tolak ukur penerapan manajemen pengelolaan limbah konstruksi, hanya 2 (dua) poin rencana yang terealisasikan. Terdapat 2 (dua) tolak ukur yang tidak memenuhi nilai rencana yaitu melakukan optimasi dalam pemakaian material sehingga menciptakan pengurangan timbunan sampah konstruksi dan laporan pendaur ulangan sampah konstruksi. Sehingga hanya mendapatkan 5 (lima) poin yang terealisasi dari 13 (tiga belas) poin rencana.

\section{d. Penerapan konservasi air pada pelaksanaan konsturksi}

Tujuan konservasi air dicapai dengan keseimbangan muka air tanah, yang diperlukan untuk mengurangi dampak pelaksanaan, khususnya di zona konstruksi. Optimalisasi penggunaan air ini dilakukan dengan menggunakan prinsip 3R (menggunakan kembali, mengurangi, dan mendaur ulang) dan semaksimal mungkin, menghasilkan kembalinya air ke lingkungan (Sutrisno \& Hamdani, 2019).

Tabel 5

Kuisioner form penilaian ketercapaian konservasi air

\begin{tabular}{|c|c|c|c|}
\hline No & Persyaratan & Point & \\
\hline A. & Konservasi Air Pada Pelaksanaan & Rencana & Realisai \\
\hline \multirow[t]{4}{*}{ a. } & Pengelolan air hujan & & \\
\hline & - Memiliki sumur serapan & 2 & \\
\hline & - Memiliki kolam penampungan air hujan & 2 & \\
\hline & $\begin{array}{l}\text { - Memiliki Kolam penampungan air hujan dengan } \\
\text { kapasitas yang besar }\end{array}$ & 3 & \\
\hline \multirow[t]{3}{*}{ b. } & Pemanfaat air hujan & & \\
\hline & $\begin{array}{l}\text { - Air hujan dimanfaatkan sebagai sumber air bersih } \\
\text { untuk kontruksi }\end{array}$ & 2 & \\
\hline & $\begin{array}{l}\text { - Memiliki sistem penahan air permukaan sehingga } \\
\text { memiliki waktu yang cukup untuk didapat }\end{array}$ & 3 & \\
\hline \multirow[t]{3}{*}{ c. } & Dewatering & & \\
\hline & $\begin{array}{l}\text { - Proyek tidak melakukan kegiatan dewatering } \\
\text { mendapatkan nilai penuh }\end{array}$ & 1 & 8 \\
\hline & $\begin{array}{l}\text { - Proyek kontruksi melakukan proses dewatering } \\
\text { yang telah memiliki ijin }\end{array}$ & 1 & \\
\hline
\end{tabular}




\begin{tabular}{lll}
\hline$\bullet$ & $\begin{array}{l}\text { Proyek kontruksi melakukan proses dewatering, } \\
\text { Memiliki skenario Dewatering }\end{array}$ & 1 \\
\hline & $\begin{array}{l}\text { Proyek kontruksi melakukan proses dewatering, } \\
\text { memiliki sumur pantau }\end{array}$ & 1 \\
\hline & $\begin{array}{l}\text { Proyek kontruksi melakukan proses dewatering, } \\
\text { Melakukan pengamatan penurunan air tanah }\end{array}$ & 1 \\
\hline$\bullet \quad$ Proyek kontruksi yang mengolah air dewatering, & 3 \\
\hline$\bullet \quad \begin{array}{l}\text { Proyek memanfaatkan air Dewatering sebagai } \\
\text { sumber air untuk kontruksi }\end{array}$ & 20 & 8 \\
\hline
\end{tabular}

Dari 3 (tiga) tolak ukur penerapan konservasi air pada pelaksanaan konsturksi, hanya 1 (satu) tolak ukur rencana yang terealisasikan yaitu proyek tidak melakukan kegiatan dewatering sehingga mendapatkan nilai penuh yaitu 8 (delapan) poin . Sehingga hanya mendapatkan 8 (delapan) poin yang terealisasi dari 20 (dua puluh) poin rencana.

e. Penerapan konservasi energi pada pelaksanaan konstruksi

Tujuan konservasi energi selama konstruksi dicapai dengan menggunakan sistem manajemen energi yang berfokus pada efisiensi dan penggunaan bahan energi yang paling efisien.

Tabel 6

Kuisioner form penilaian ketercapaian konservasi air

\begin{tabular}{|c|c|c|c|}
\hline No & Persyaratan & Point & \\
\hline A. & Konservasi Energi Pada Pelaksanaan Kontruksi & Rencana & Realisai \\
\hline \multirow[t]{6}{*}{ a. } & Managemen energi saat kontruksi & & \\
\hline & - Memiliki perencaaan saat kontruksi & 1 & $\mathrm{~T}$ \\
\hline & - Memiliki sop sesuai dengan ketentuan diatas & 2 & $\mathrm{~T}$ \\
\hline & $\begin{array}{l}\text { - Melaksanakan SOP, dibuktikan dengan hasil } \\
\text { penggunaan energi sesuai dengan rencana }\end{array}$ & 2 & $\mathrm{~T}$ \\
\hline & $\begin{array}{l}\text { - Melakukan manajemen energi saat pelaksanaan } \\
\text { kontruksi }\end{array}$ & 2 & $\mathrm{~T}$ \\
\hline & Total & 7 & \\
\hline \multirow[t]{6}{*}{ b. } & Sistem Kelistrikan saat kontruksi & & \\
\hline & $\begin{array}{l}\text { - Menggunakan peralatan yang telah lulus uji emisi } \\
\text { (jika menggunakan genset) }\end{array}$ & 1 & $\mathrm{~T}$ \\
\hline & $\begin{array}{l}\text { - Memasang KWH meter pada flannel induk dan } \\
\text { panel }\end{array}$ & 2 & $\mathrm{~T}$ \\
\hline & - indrustri & & \\
\hline & $\begin{array}{l}\text { - Dilakukan monitoring dan evaluasi secara berkala } \\
\text { beserta Langkah-Langkah perbaikan }\end{array}$ & 2 & $\mathrm{~T}$ \\
\hline & - Tata cara persyaratan dan detail penerapan & 2 & $\mathrm{~T}$ \\
\hline
\end{tabular}




\begin{tabular}{lll}
\hline $\begin{array}{l}\text { konservasi energi pada pelaksanaan kontruksi sesuai } \\
\text { dengan ketentuan tokoh }\end{array}$ & 7 \\
\hline Total & \\
\hline Total 14 \\
\hline
\end{tabular}

Dari 2 (dua) tolak ukur penerapan konservasi energi pada pelaksanaan konstruksi, hanya 1 (satu) tolak ukur rencana yang terealisasikan yaitu pada bagian memasang KWH meter pada panel induk dan panel distribusi dan monitoring dan evaluasi secara berkala beserta langkah langkah perbaikan. Sehingga hanya mendapatkan 4 (empat) poin yang terealisasi dari 14 (empat belas) poin rencana (Rahayu \& Pranowo, 2012).

\section{Praktik Perilaku Hijau}

Berdasarkan SE no 86 tahun 2016, Green Construction harus memiliki metode kerja dan teknologi yang dapat memaksimalkan nilai yang dapat dikeluarkan sekaligus meminimalkan jumlah waktu yang dihabiskan pada setiap tahapan eksposisi konstruksi.

a. Penerapan sistem manajemen kesehan dan keselamatan kerja (SMK3)

Tujuan SMK3 adalah untuk memberikan perlindungan terbaik bagi kesehatan dan keselamatan pekerja sebagai akibat dari penyelesaian proyek konstruksi. Kesejahteraan manusia di wilayah proyek akan menguntungkan proyek itu sendiri serta lingkungan sekitarnya.

Tabel 7

Kuisioner form penilaian sistem manajemen kesehatan dan keselamatan kerja

\begin{tabular}{|c|c|c|c|}
\hline No & Persyaratan & \multicolumn{2}{|c|}{ Point } \\
\hline 1 & $\begin{array}{l}\text { Penerapan sistem manajemen kesehatan dan } \\
\text { keselamatan }\end{array}$ & Rencana & Tercapai \\
\hline \multirow[t]{7}{*}{ a. } & Manajemen Energi saat kontruksi & & \\
\hline & $\begin{array}{l}\text { - Memiliki metode pengingat K3L melalui } \\
\text { secara berkala }\end{array}$ & 1 & 1 \\
\hline & $\begin{array}{l}\text { - Menjelaskan tentang ketentuan baju dan } \\
\text { peralatan keselamatan }\end{array}$ & 2 & 2 \\
\hline & $\begin{array}{l}\text { - Dalam dokumen K3 memiliki SOP untuk } \\
\text { setiap jenis pekerjaan }\end{array}$ & 2 & 2 \\
\hline & $\begin{array}{l}\text { - Terdapat rambu rambu K3 pada proyek } \\
\text { kontruksi baru }\end{array}$ & 2 & 2 \\
\hline & $\begin{array}{l}\text { - Terdapat induksi kepada pekerja kontruksi } \\
\text { baru }\end{array}$ & 1 & 1 \\
\hline & Total & 8 & 8 \\
\hline b. & $\begin{array}{l}\text { Melakukan usaha pencegahan usaha timbulnya } \\
\text { penyakit akibat kontruksi }\end{array}$ & 1 & 1 \\
\hline c & Menciptakan lingkungan kerja yang aman dan & & \\
\hline
\end{tabular}




\begin{tabular}{|c|c|c|}
\hline nyaman & & \\
\hline $\begin{array}{l}\text { - Memberikan mess pekerjaan yang aman dan } \\
\text { nyaman }\end{array}$ & 2 & 2 \\
\hline - Menyediakan toilet yang layak pakai & 2 & 2 \\
\hline Total & 5 & 5 \\
\hline & 13 & 13 \\
\hline
\end{tabular}

Dari 3 (tiga) tolak ukur penenilaian Penerapan Sistem Manajemen Kesehatan dan Keselamatan Kerja (SMK3) proyek pasar rakyat kota Pariaman mendapatkan poin penuh yaitu 13 (tiga belas) poin terealisasi dari 13 (tiga belas) poin rencana.

b. Penerapan Perilaku Ramah Lingkungan

Tujuan dari perilaku ramah lingkungan merupakan perilaku yang harus diterapkan oleh setiap individu pekerja yang terlibat pada tahap pelaksanaan konstruksi guna mengurangi dampak negatif dari pelaksanaan konstruksi terhadap lingkungan. Perilaku ini dilakukan dengan menitikberatkan pada prinsip-prinsip penghematan energi, air dan penggunaan sumber daya.

Tabel 8

Kuisioner form penilaian penerapan perilaku ramah lingkungan

\begin{tabular}{clcc}
\hline No & \multicolumn{1}{c}{ Persyaratan } & \multicolumn{2}{c}{ Point } \\
\hline 2. & \multicolumn{1}{c}{ Penerapan Perilaku Ramah Lingkungan } & Rencana & Realisasi \\
\hline a. & $\begin{array}{l}\text { Aktifitas Konstruksi memperhatikan potensi negative } \\
\text { terhadap lingkungan }\end{array}$ & 3 & 3 \\
\hline b. & Melakukan kegiatan penghematan energi & 3 & 3 \\
\hline c. & Melakukan kegiatan konsrvasi air & 3 & \\
\hline d. & Melakukan kegiatan penghematan sumber daya & 3 & 6 \\
\hline & Total & 12 & 6 \\
\hline
\end{tabular}

Dari 4 (empat) tolak ukur penerapan perilaku ramah lingkungan, terdapat 2 (dua) tolak ukur rencana yang tidak terealisasikan yaitu melakukan kegiatan konservasi air dan kegiatan penghematan sumber daya. Sehingga hanya mendapatkan 6 (empat) poin yang terealisasi dari 12 (dua belas) poin rencana.

\section{Rantai Pasok Hijau}

Rantai pasokan hijau dalam proses konstruksi $\mathrm{BGH}$ diperoleh dari pemasok dan sub-pelaksana/sub-kontraktor yang berkontribusi dalam melaksanakan konstruksi dengan mempertimbangkan durasi proses hidup pasokan, dengan mempertimbangkan penggunaan bahan dalam eksposisi ini disorot oleh penggunaan 
bahan selama proses. konstruksi. Alhasil, bahan-bahan yang digunakan dalam pembangunan tidak berbahaya.

a. Penggunaan Material Konstruksi

Penggunaan material selama proses konstruksi harus dilakukan seefisien mungkin untuk meningkatkan efisiensi sumber daya dan mengurangi limbah konstruksi berbasis material.

\section{Tabel 9}

Kuisioner form penilaian penggunaan material konstruksi

\begin{tabular}{clcc}
\hline No & \multicolumn{1}{c}{ Persyaratan } & \multicolumn{2}{c}{ Point } \\
\hline 1. & Penggunaan material Konstruksi & Rencana & Realisasi \\
\hline a. & $\begin{array}{l}\text { Dalam proses kontruksi menggunakan material yang } \\
\text { bahan baku berasal dari indonesia }\end{array}$ & 3 & 3 \\
\hline b. & $\begin{array}{l}\text { Dalam proses kontruksi menggunakan material yang } \\
\text { ramah lingkungan }\end{array}$ & 3 & 3 \\
\hline c. & $\begin{array}{l}\text { Rencana pengiriman dan pemafaatn material dilakukan } \\
\text { dengan tepat sesuai dengan kriteria diatas }\end{array}$ & 1 & 1 \\
\hline d. & Rencana penggunaan alat berat dilakukan dengan tepat & 1 & 1 \\
\hline e. & $\begin{array}{l}\text { Material yang digunakan memiliki sedikit kemasan } \\
\text { pembungkus }\end{array}$ & 2 & 2 \\
\hline & \multicolumn{1}{c}{ Total } & 10 & 10 \\
\hline
\end{tabular}

Dari 5 (lima) tolak ukur penerapan perilaku ramah lingkungan, proyek berhasil merealisasikan seluruh poin pada form penilaian. Sehingga pada penggunaan material konstruksi ini proyek mendapatkan 10 (sepuluh) poin yang terealisasi dari 10 (sepuluh) poin rencana.

b. Pemilihan Pemasok dan/atau Sub kontraktor

Rantai pasokan hijau di BGH dapat dipantau oleh pemasok bahan yang ditawarkan di lokasi proyek.

Tabel 10

Kuisioner form penilaian pemilihan pemasok dan/ sub konstraktor

\begin{tabular}{clcc}
\hline No & \multicolumn{1}{c}{ Persyaratan } & \multicolumn{2}{c}{ Point } \\
\hline 1. & Pemilihan Pemasok dan atau sub Kontraktor & Rencana & Realisasi \\
\hline a. & $\begin{array}{l}\text { Pemasok material atau alat beralamat deket alamat } \\
\text { dengan lokasi proyek }\end{array}$ & 4 & 4 \\
\hline b. & Pemasok alat atau material produknya buatan indonesi & 5 & 5 \\
\hline & Total & 9 & 9 \\
\hline
\end{tabular}

Dari 2 (dua) tolak ukur pemilihan pemasok dan sub kontraktor, proyek berhasil merealisasikan seluruh poin pada form penilaian. Sehingga pada pemilihan pemasok dan sub kontraktor ini proyek mendapatkan 9 (sembilan) poin yang terealisasi dari 9 (sembilan) poin rencana.

\section{Kesimpulan}


Setelah melakukan penelitian ada beberapa pertanyaan yang didapat sepeti: (1.) Gedung pasar rakyat kota Pariaman mendapatkan nilai penuh pada tiga bagian syarat kelayakan bangunan dari sepuluh bagian syarat kelayakan bangunan sebagai berikut : (a.) Pada penerapan sistem manajemen kesehatan dan keselamatan kerja proyek mendaptkan 13 poin realisasi dari 13 poin rencana (b.) Pada penggunaan materil konstruksi proyek mendaptkan 10 poin realisasi dari 13 poin rencana (c.) Pada pemilihan pemasok dan sub kontraktor proyek mendaptkan 9 poin realisasi dari 9 poin rencana. (2.) Gedung pasar rakyat kota Pariaman hanya memenuhi sebagian syarat kelayakan bangunan hijau pada beberapa bagian persyaratan, diantaranya sebagai berikut : (a.) Pada metode konstruksi hijau proyek mendapatkan 3 poin realisasi dari 4 poin rencana dimana proyek tidak menunjukkan adanya bukti inovasi-inovasi dalam proses konstruki sehingga kehilangan satu poin. (b.) Pada pengoptrimalan penggunaan peralatan proyek mendapatkan 4 poin realisasi dari 5 poin rencana dimana proyek kehilangan 1 poin karna tidak berhasil meminimalkan waktu jeda operasional alat berat. (c.) Pada penerapan manajemen pengelolaan limbah konstruksi proyek mendapatkan 5 poin realisasi dari 13 poin rencana dan kehilangan 8 poin karena tidak melakukan optimasi dalam pemakaian material sehingga menciptakan pengurangan timbunan sampah konstruksi dan tidak memilki laporan pendaur ulangan sampah konstruksi (d.) Pada konservasi air pada pelaksanaan konstruksi proyek mendapatkan 8 poin realisasi dari 20 poin rencana dan kehilangan 12 poin, karena tidak melakukan pengelolaan air hujan, pemanfaatan air hujan dan dewatering. (e.) Pada penerapan konservasi energi pelaksanaan konstruksi proyek mendapatkan 4 poin realisasi dari 14 poin rencana dan kehilangan 10 poin, karena proyek tidak melakukan manajemen energi saat konstruksi dan hanya melakukan sebagian sistem kelistrikan saatt konstruksi. (f.) Pada kegiatan penghematan sumberdaya proyek mendapatkan 6 poin realisasi dari 12 poin rencana dan kehilangan 6 poin, karena tidak melakukan kegiatan konservasi air dan kegiatan penghematan sumber daya. (g.) Pada kegiatan konservasi energi tahap pelaksanaan konstruksi proyek tidak melakukannya, sehingga pada bagian ini proyek tidak mendapatkan poin. (3.) Gedung pasar rakyat kota Pariaman memperoleh poin dengan kategori yaitu untuk Proses Konstruksi Hijau memperoleh 27 poin dengan persentase 27\%, untuk Praktek Perilaku Hijau memperoleh 18 poin dengan persentase $18 \%$ dan untuk Ramtai Pasok Hijau memperoleh 19 poin dengan persentase 19\%. Total poin 64 poin dengan persentase $64 \%$, sehingga belum bisa dikatakan bangunan hijau menurut SE no 86 tahun 2016. Adapun untuk dapat masuk perangkat dasar tersertifikasi harus memenuhi tolak ukur SE no 86 tahun 2016 agar tercapai persentase minimal yang diisyaratkan yaitu Plakat Pratama dengan terpenuhinya 70\% s.d. $75 \%$ dari nilai total. 
Tri Rahmi Nurman

\section{BIBLIOGRAFI}

Anggito, Albi, \& Setiawan, Johan. (2018). Metodologi penelitian kualitatif. CV Jejak (Jejak Publisher).Google Scholar

Beda, Alfonsus Bayu Adi Pratama. (2014). Bangunan Industri Karoseri Bis Di Palembang. Sekolah Tinggi Teknik Musik. Google Scholar

Duane, Gina Evla. (2016). Aplikasi Transaksi Pembelian Secara Kredit Dan Tunai Pada Pt. Dwi Mitra Jaya Lestari Palembang. Politeknik Negeri Sriwijaya. Google Scholar

Joga, Nirwono. (2017). Gerakan Kota Hijau 2.0: Kota Cerdas Berkelanjutan. Gramedia Pustaka Utama. Google Scholar

Mahyuddin, Erwin Reggynal, Rilatupa, James, \& Marpaung, Charles O. P. (2020). Optimasi Façade Kantor Dinas Pendidikan Provinsi Dki Jakarta, Jalan Gatot Subroto Kavling 40-41, Jakarta Dengan Konsep Bangunan Hijau. Google Scholar

Mulyadi, Winer. (2012). Standardisasi bangunan hijau pada bangunan. Universitas Pelita Harapan. Google Scholar

Nugroho, Agung Cahyo. (2011). Sertifikasi Arsitektur/Bangunan Hijau: Menuju Bangunan yang Ramah Lingkungan. Jurnal Arsitektur, 2(1). Google Scholar

Perdana, Regy Citra, Agustino, Muhammad Risqi, Hartawan, Dedi, Suyoso, Yosart Adi, \& Sari, Ratna. (2020). Adaptasi dan Kebiasaan Baru Human Resource Department di Masa Pandemik Covid-19. Business Innovation and Entrepreneurship Journal, 2(3), 201-204. Google Scholar

Pratama, Riza. (2019). Efek Rumah Kaca Terhadap Bumi. Buletin Utama Teknik, 14(2), 120-126. Google Scholar 
Rahayu, Aprilia Tri, \& Pranowo, Bambang. (2012). Analisis pengaruh tingkat suku bunga deposito bank konvensional terhadap deposito mudharabah pada bank syariah di Indonesia. Jurnal Ekonomi Dan Studi Pembangunan, 4(1), 93-104. Google Scholar

Saidal Siburian, M. M., \& Mar, M. (2020). Pencemaran Udara dan Emisi Gas Rumah Kaca. Kreasi Cendekia Pustaka. Google Scholar

Setyosari, H. Punaji. (2016). Metode penelitian pendidikan \& pengembangan. Prenada Media. Google Scholar

Sutrisno, Nono, \& Hamdani, Adang. (2019). Optimalisasi pemanfaatan sumber daya air untuk meningkatkan produksi pertanian. Jurnal Sumberdaya Lahan, 13(2), 73-88. Google Scholar

Wijaya, Hengki. (2020). Analisis Data Kualitatif Teori Konsep dalam Penelitian Pendidikan. Sekolah Tinggi Theologia Jaffray. Google Scholar

Zed, Mestika. (2012). Inventarisasi dan Rekontruksi Sejarah Gempa 30 September 2009 di Kota Padang Melalui Film Dokumentasi. Google Scholar

\section{Copyright holder:}

Tri Rahmi Nurman (2021)

First publication right:

Syntax Idea

\section{This article is licensed under:}

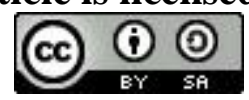

